\title{
Lipoxins: nature's way to resolve inflammation
}

This article was published in the following Dove Press journal:

Journal of Inflammation Research

30 September 2015

Number of times this article has been viewed

\section{Jayashree $A$}

\section{Chandrasekharan}

Neelam Sharma-Walia

HM Bligh Cancer Research Laboratories, Department of Microbiology and Immunology, Chicago Medical School, Rosalind Franklin University of Medicine and Science, North Chicago, IL, USA

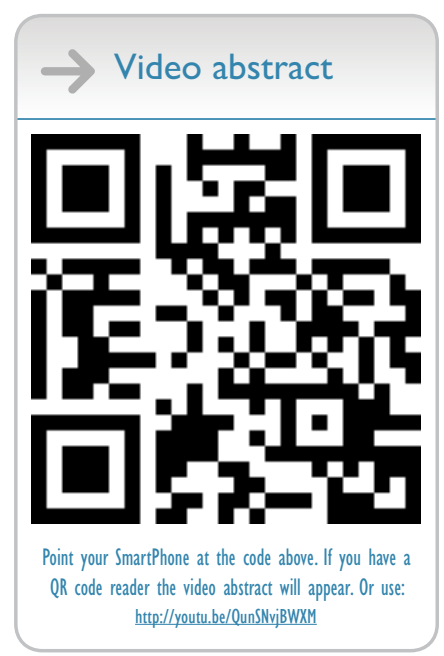

Correspondence: Neelam Sharma-Walia HM Bligh Cancer Research Laboratories, Department of Microbiology and Immunology, Chicago Medical School, Rosalind Franklin University of Medicine and Science, 3333 Green Bay Road, North Chicago, IL 60064, USA Email neelam.sharma-walia@ rosalindfranklin.edu
Abstract: An effective host defense mechanism involves inflammation to eliminate pathogens from the site of infection, followed by the resolution of inflammation and the restoration of tissue homeostasis. Lipoxins are endogenous anti-inflammatory, pro-resolving molecules that play a vital role in reducing excessive tissue injury and chronic inflammation. In this review, the mechanisms of action of lipoxins at the site of inflammation and their interaction with other cellular signaling molecules and transcription factors are discussed. Emphasis has also been placed on immune modulatory role(s) of lipoxins. Lipoxins regulate components of both the innate and adaptive immune systems including neutrophils, macrophages, T-, and B-cells. Lipoxins also modulate levels of various transcription factors such as nuclear factor $\kappa \mathrm{B}$, activator protein-1, nerve growth factor-regulated factor $1 \mathrm{~A}$ binding protein 1 , and peroxisome proliferator activated receptor $\gamma$ and control the expression of many inflammatory genes. Since lipoxins and aspirin-triggered lipoxins have clinical relevance, we discuss their important role in clinical research to treat a wide range of diseases like inflammatory disorders, renal fibrosis, cerebral ischemia, and cancer. A brief overview of lipoxins in viral malignancies and viral pathogenesis especially the unexplored role of lipoxins in Kaposi's sarcoma-associated herpes virus biology is also presented.

Keywords: lipoxins, epi-lipoxins, inflammation, pro-resolving, aspirin-triggered lipoxins, cyclooxygenases, lipoxygenases, therapeutic potential, transcription factors, Kaposi's sarcomaassociated herpes virus

\section{Introduction}

In response to infection, injury, and inflammatory stimuli, chemical mediators are released as regulators of immune response. Lipoxins are one such anti-inflammatory, pro-resolving molecule that is secreted by immune cells such as neutrophils and macrophages. ${ }^{1,2}$ Lipoxins were first isolated from human leukocytes by Serhan et al and were first described as a novel series of compounds with four conjugated double bonds. ${ }^{3}$ Lipoxins are a metabolite of the arachidonic acid pathway, which was well studied by Hamberg and Samuelsson. ${ }^{4}$ Arachidonic acid pathways play an important role in inflammation, producing several anti-inflammatory molecules. ${ }^{5}$

Lipoxins can be synthesized by two major routes from arachidonic acid. Additionally, lipoxin epimers can be formed under the influence of aspirin treatment as described by Serhan et $\mathrm{al}^{3}$ (Figure 1). There are three major lipoxygenases (LO) that are involved in lipoxin synthesis from arachidonic acid such as 5-LO, 15-LO, and 12-LO. The first route of lipoxin synthesis occurs in platelets where leukotriene A4 is acted upon by $12-\mathrm{LO}$, and is converted to lipoxins. ${ }^{6}$ The second route of synthesis of lipoxins involves the action of a series of LO (5-LO in neutrophils and 15-LO in 


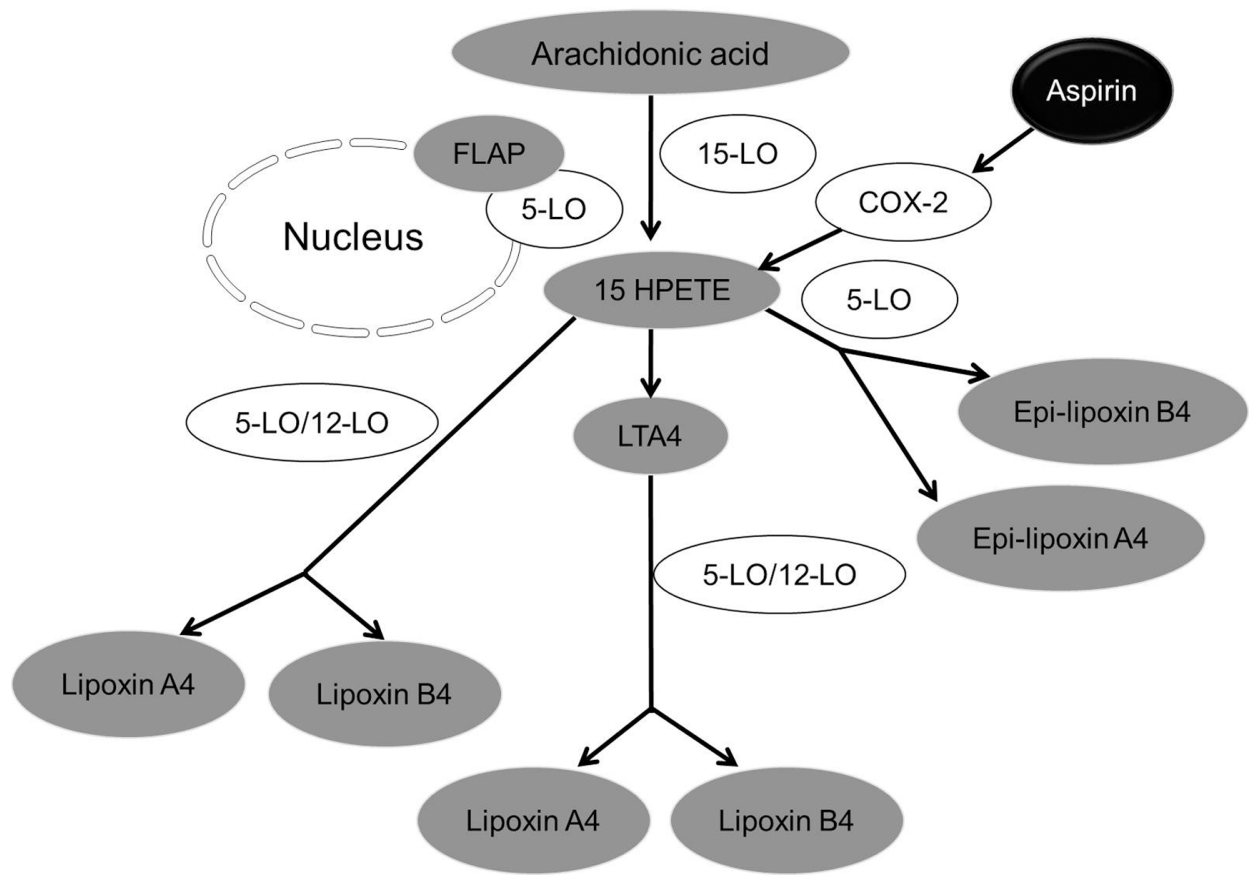

Figure I Synthesis of lipoxin. Three major lipoxygenases (LO) such as 5-LO, 15-LO, and I2-LO are involved in lipoxin synthesis from arachidonic acid. Notes: In the first route of lipoxin synthesis LTA4 is acted upon by 12-LO, and is converted to lipoxins. The second route of synthesis of lipoxins involves the action of a series of lipoxygenase (5-LO in neutrophils and I5-LO in erythrocytes) activities on arachidonic acid which then gets converted to I5-HEPTE. Lipoxins are formed from I5-HEPTE by the action of either 5-LO or I2-LO. The third route is the formation of epi-lipoxin A4 or aspirin-triggered lipoxin (ATL) and epi-lipoxin B4 whose generation is aspirin dependent. No fill represent enzymes whereas the gray filled represent the metabolites or end products.

Abbreviations: I5-HPETE, I5-hydroxyperoxyeicosatetraenoic acid; COX-2, cyclooxygenase-2; FLAP, 5-lipoxygenase-activating protein; LTA4, leukotriene A4.

erythrocytes and reticulocytes) activities on arachidonic acid. Arachidonic acid then gets converted to 15-hydroxype roxyeicosatetraenoic acid, which is subsequently converted to lipoxin A and lipoxin B. ${ }^{3}$ The third route is dependent on aspirin and leads to the generation of 15 epi-lipoxin A4, also known as aspirin-triggered lipoxin (ATL) and 15 epi-lipoxin B4. ${ }^{7}$ Aspirin is clinically used as analgesic, antipyretic, anticancer drug, and also recently used in cardiovascular protection. ${ }^{89}$ Aspirin acetylates cyclooxygenase-2 (COX-2) to form 15R-hydroxy eicosatetraenoic acid. Epi-lipoxins are formed when 15R-hydroxy eicosatetraenoic acid is metabolized by 5-LO. ${ }^{7}$ Aspirin is found to have a sex-dependent impact on epi-lipoxin formation. ${ }^{10}$ Plasma epi-lipoxin levels increase with age in women taking low doses of aspirin, while it decreases with age in men. ${ }^{11}$ This study rationales the use of aspirin in elderly women to treat aging-related inflammatory conditions. Recently conducted double-blinded clinical trial with healthy subjects showed that low-dose aspirin $(81 \mathrm{mg}$ daily) significantly increased aspirin-triggered 15 -epi-lipoxin A4 levels. ${ }^{11}$ Lipoxins also have sex-dependent impact as it has been shown to interact with estrogen receptor ${ }^{12}$ and may be used as a potential to treat endometriosis..$^{13}$ Statins, which are potent cholesterol-lowering drugs, are also found to trigger 15-epi-lipoxin A4 formation. Statins act by decreasing soluble epoxide hydrolase activity to increase 14,15-epoxyeicosatrienoic acid that influences arachidonate conversion to 15-epi-lipoxins. ${ }^{14,15}$ Aspirin, together with statins, enhances epi-lipoxin formation. Additionally, aspirin initiated nitric oxide amplifies epi-lipoxin formation by nitrosylation of statin-induced COX-2. ${ }^{15,16}$

Lipoxins and epi-lipoxins exert their anti-inflammatory effects through signals generated by binding to a high-affinity, G protein-coupled lipoxin A4 receptor (ALX)/formyl peptide receptor (FPR2). ${ }^{17}$ Lipoxins have also been found to interact with other receptors like $\mathrm{G}$ protein-coupled receptor 32 (GPR 32), Aryl hydrocarbon receptor, ${ }^{18}$ estrogen receptor, ${ }^{12}$ and high affinity cysteinyl leukotriene receptor. ${ }^{19}$ Lipoxins are rapidly metabolized, the major routes of degradation being dehydrogenation at $\mathrm{C}-15$ and possibly $\omega$-oxidation at $\mathrm{C}-20 .{ }^{17}$ To circumvent such metabolic inactivation, stable synthetic analogs have been developed that are modified at C-15, C-16, and/or C-20. These compounds retain the biological activity of native lipoxins and have been shown to bind with higher affinity to ALX/FPR2, resulting in greater potency. ${ }^{17}$ The enhanced stability and improved efficacy of these analogs following local and systemic administration in models of inflammation and ischemia-reperfusion suggests significant therapeutic potential. ${ }^{20}$ Aspirin, the leading non-steroidal 
anti-inflammatory drug, has remained the most successful analgesic-antipyretic therapeutic available for human use for more than 100 years and many new functions continue to be discovered. ${ }^{8,21-25}$ Aspirin is known to affect biosynthesis of lipid mediators involved in pro-inflammatory pathways. ${ }^{26}$ Mechanisms responsible for aspirin's anti-inflammatory, analgesic-antipyretic properties remain of considerable interest. In particular, new "super-aspirins" are developed to be more gastro protective and do not possess the deleterious side effects of steroids. ${ }^{27}$ New super-aspirins, in addition to inhibiting pro-inflammatory prostaglandin formation, trigger the simultaneous endogenous generation of novel carbon 15-epimers of lipoxins, also called ATLs, by transcellular routes during inflammation in vivo. ${ }^{28}$ ATLs are 100 times more potent than aspirin. ${ }^{29}$ The anti-inflammatory activity of lipoxins is extremely effective due to their high potency, high bioavailability, low IC50, and safety, with minimal unwanted side effects such as gastrointestinal tract ulcer formation, bronchoconstriction, and altered glomerular functions..$^{17,30-37}$ Lipoxins are safe, antifibrotic, and pro-myelopoietic. ${ }^{29}$

Lipoxin and epi-lipoxin interact with ALX/FPR2 and this interaction leads to triggering of several cellular events that occur within seconds or minutes (Figure 2). A study conducted on human umbilical vein endothelial cells shows that there is substantial internalization of ALX/FPR2 to the perinuclear region upon stimulation with lipoxin. ${ }^{38}$ Internalization of ALX/FPR2 is critical for the antiinflammatory action of lipoxins. ${ }^{34}$

ALX/FPR2 internalization upon lipoxin stimulation occurs in a time-dependent manner. ${ }^{33,34} \mathrm{~A}$ study by Maderna et al shows that in unstimulated cells, ALX is found predominantly on the cell surface. After 5 minutes of lipoxin stimulation, ALX could be found on both the inner and outer leaflets of the plasma membrane. After 15 minutes, ALX is found in the endosome and subsequently in the late endosomelysosome compartment. After 120 minutes, ALX resumes

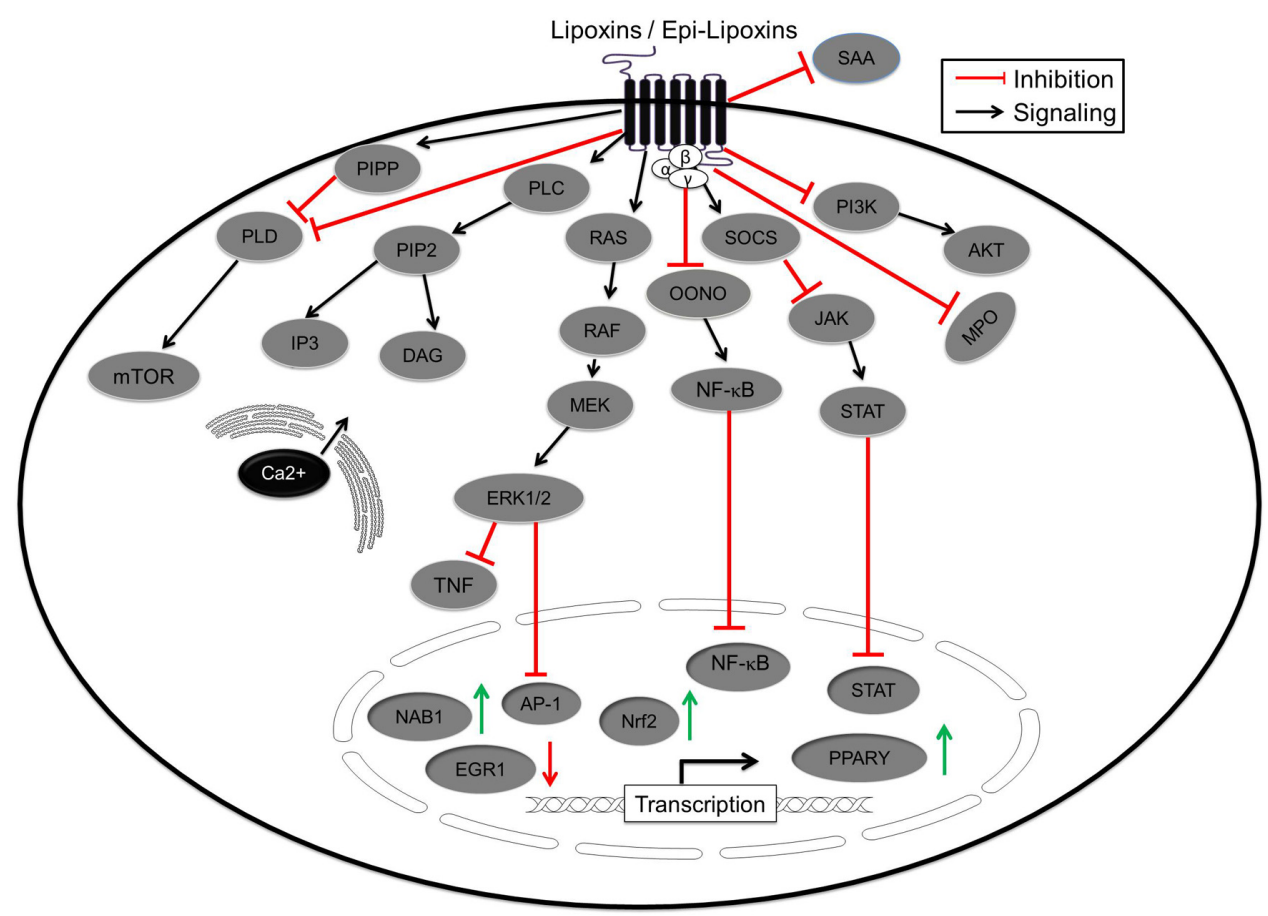

Figure 2 Effect of lipoxins on cytoplasmic signaling cascades and transcription factors.

Notes: Lipoxin binds to its $G$ protein-coupled receptor ALX/Formyl peptidyl receptor triggering a wide array of cytoplasmic signaling cascades. Binding of lipoxin to its receptor ALX prevents binding of other pro-inflammatory ligands like SAA. Lipoxins could have alternative effects on PI3K and AKT pathway depending on the cell type. Lipoxins can control proliferation of immune cells and cancer cells by inhibiting growth promoting PI3K and AKT pathways. Lipoxins act to resolve inflammation by activating PI3K and AKT in macrophages to increase their life span. Lipoxin modulates levels of neutrophil for effective mounting and resolution of inflammation. They recruit neutrophils at the site of inflammation by increasing the cytosolic calcium levels and initiating pseudopodia movement, and at the same time control their proliferation by blocking MPO. Lipoxin controls synthesis and release of pro-inflammatory cytokines by increasing the mRNA level of suppressors of cytokine signaling and prevent transcription of inflammatory cytokines like IL-8 by inhibiting nuclear accumulation of NFKB and AP-I. Lipoxins are anti-angiogenic by blocking TNF $\alpha$ signaling. Lipoxins control the expression of inflammatory genes by decreasing levels of NFKB and AP-I in the nucleus and increasing the levels of NABI, Nrf2, and PPAR $\gamma$. Green arrows indicate induction and red arrows indicate reduction in expression. Black lines indicate downstream biological events.

Abbreviations: AP-I, activator protein-I; DAG, diacyl-glycerol; EGRI, early growth response I gene; ERK, extracellular signal-regulated kinase; IL-8, interleukin 8; IP3, inositol triphosphate; JAK, Janus kinase; MEK, mitogen-activated protein kinase kinase; MPO, myeloperoxidase; mTOR, mammalian target of rapamycin; NABI, NGFIA binding protein I; NFKB, Nuclear factor KB; Nrf2, nuclear factor like 2; ONOO, peroxonitrite anion; PI3K, phosphatidylinositol-4,5-bisphosphate 3-kinase; PLD, phospholipase D; PPAR, peroxisome proliferator activated receptor; SAA, serum amyloid A; TNF $\alpha$, tumor necrosis factor alpha; SOCS, suppressors of cytokine signaling; PIPP, polyisoprenyl phosphate. 
its surface expression. ${ }^{39}$ Internalization of ALX receptor is critical for phagocytosis. ${ }^{35}$ Maderna et al have shown that internalization of the receptor is affected by treatment with phospho-kinase $\mathrm{C}$ inhibitor. Phospho-kinase $\mathrm{C}$ was found to be involved in internalization of the ALX receptor by caveolin-mediated endocytosis that also involves lipid rafts. Lipoxins induce phagocytosis of apoptotic cells through rearrangement of actin filaments. The internalization of ALX/FPR2 to lipid rafts could directly contribute to actin rearrangement and aid in phagocytosis. ${ }^{39,40}$

\section{Role of lipoxins at the site of inflammation}

Neutrophils play a vital role in the innate immune response against infections. ${ }^{41}$ Timely recruitment of neutrophils to the site of inflammation followed by their clearance helps in resolving inflammation. ${ }^{42,43}$ Lipoxins help in migration of neutrophils to the site of inflammation by increasing their cytosolic calcium $\left(\mathrm{Ca}^{2+}\right)$ levels. ${ }^{44}$ An increase in $\mathrm{Ca}^{2+}$ promotes assembly of cytoskeletal elements, which help the neutrophils to extend their pseudopods and initiate transendothelial migration. ${ }^{45}$ Neutrophils also need to be cleared from the site of inflammation after acting on a particular pathogen. Balance in the neutrophil life cycle is essential to avoid damage to the tissues. ${ }^{46}$ Delayed apoptosis of neutrophils is one of the major causes of diseases such as acute respiratory syndrome ${ }^{47}$ and cancer. ${ }^{48}$ Lipoxins also help in clearing neutrophils from the site of infection and resolve the inflammation.

Myeloperoxidase (MPO), secreted by azurophil granules of neutrophils, has a dual function. Firstly, it can destroy pathogens by forming a highly reactive halide-derived oxidant, and secondly, it can rescue human neutrophils from constitutive apoptosis and prolong their life span via the adhesion molecule cluster of differentiation (CD) $11 \mathrm{~b}$ (CD11b)/CD18. ${ }^{49,50}$ The powerful anti-apoptosis signal from MPO is nullified by 15 -epi-lipoxin, thus redirecting neutrophils to apoptosis and promoting the resolution of inflammation. ${ }^{51} \mathrm{~A}$ recent study indicates that the acute-phase protein serum amyloid A (SAA) also prolongs neutrophil longevity by suppressing constitutive apoptosis. ${ }^{51} \mathrm{SAA}$ and lipoxins have the same binding receptor: ALX/FPR2 on the surface of neutrophils. ${ }^{52}$ Binding of epi-lipoxin or lipoxin to ALX opposes the action of SAA and controls the life cycle balance of neutrophils by resolving inflammation. ${ }^{52}$ Lipoxins and ATLs evoke bio actions in a range of physiologic and pathophysiologic processes and serve as endogenous lipid mediators that cease neutrophil infiltration and initiate resolution. ${ }^{44}$ Extreme leukocyte infiltration at the site of inflammation causes tissue damage. Cytokine signals from interleukin (IL)-8 and stable peroxonitrite anion (ONOO) recruit leukocytes into inflamed tissue. Decreasing the levels of IL-8 and ONOO helps in preventing development of tissue injury. ${ }^{53,54}$ Lipoxins also help in preventing tissue injury by inhibiting the formation of ONOO at the site of inflammation and attenuating the accumulation of nuclear factor $\kappa \mathrm{B}(\mathrm{NF} \kappa \mathrm{B})$ and activator protein-1 (AP-1) in the nucleus, which subsequently reduces IL- 8 production. ${ }^{55,56}$ Inhibiting IL-8 secretion also reduces neutrophil accumulation and activation. ${ }^{57}$

Macrophages are recruited to the site of infection after neutrophils. Macrophages are required to phagocytize dead cells and pathogens at the site of infection and an increase in survival of macrophages facilitates clearing of infection/ inflammation. ${ }^{58}$ Lipoxins also promote resolution of inflammation by delaying the apoptosis of macrophages. Lipoxins stimulate a rapid activation of the phosphatidylinositol-4, 5-bisphosphate 3-kinase (PI3K)/Akt and extracellular signalregulated kinase $(\mathrm{ERK}) /$ nuclear factor like 2 (Nrf2) pathways that have a relevant role in the inhibition of apoptosis in macrophages (Figure 2)..$^{59}$

Excessive adaptive immune response can lead to inflammation, damage to tissue, and autoimmune diseases. ${ }^{60}$ Decreasing antibody production after inflammation and decreasing antibody production against self-antigens are vital in resolving inflammation and preventing autoimmune diseases. ${ }^{61}$ A study by Ramon et al shows that lipoxin A4, through its receptor ALX/FPR on the B-cell surface, decreases memory B-cell antibody production and proliferation. ${ }^{62}$ In addition, T-cell secreted cytokines, such as tumor necrosis factor alpha (TNF $\alpha$ ) that promotes inflammation and diseases such as arthritis and inflammatory bowel disease, can be inhibited by lipoxin. ${ }^{63}$ Therefore, lipoxins, epi-lipoxins, and ALX may provide new opportunities to design novel "resolution-targeted" therapies, which could effectively control inflammation.

Activation of the lipoxin-mediated ALX has been shown to inhibit phospholipase D (PLD) signaling and superoxide anion generation. Among these, PLD activity has been reported to be regulated via polyisoprenyl phosphate signaling (Figure 2), which acts as a "stop" signaling switch for ATL A4. ${ }^{64}$ PLD catalyzes the conversion of phosphatidylcholine to phosphatidate and choline, and plays a key role in cell growth, proliferation, metastasis, cell transformation, angiogenesis, and mammalian target of rapamycin signaling, vesicular trafficking, and endocytosis. ${ }^{65}$ PLD represents a 
potential target for the rational development of therapeutics against cancer and inflammation-related diseases.

\section{Lipoxins and transcription factors}

A lot is known about the signaling pathways of lipoxins and their mechanism of action to resolve inflammation; however, their action on transcription factors involved in inflammation is yet to be explored. NFKB and AP-1 play an important role in controlling expression of several genes involved in inflammation, like E selectin, TNF $\alpha$, IL-8, and IL-1 $\beta .{ }^{66}$ Superoxide and nitric oxide released at the site of injury react to form the stable ONOO.${ }^{54} \mathrm{ONOO}$ increases nuclear accumulation of transcription factors like NFKB and AP-1 promoting inflammation. ${ }^{56}$ Lipoxins and epi-lipoxins inhibit the formation of $\mathrm{ONOO}$ at the site of inflammation and attenuate the accumulation of NFKB and AP-1 in the nucleus.

Lipoxins also control the expression of the early growth response 1 gene (EGR1). EGR1 is activated in antigenic stimulated T-cells. EGR1 controls the transcription of proinflammatory cytokines IL-2 and TNF $\alpha$ in T-cells. ${ }^{67}$ Apart from increasing pro-inflammatory cytokine levels, EGR1 also increases the nuclear expression of NFKB and AP-1 and contributes to tumor formation and inflammation. ${ }^{68}$ Transcriptional repressor NAB1 downregulates the expression of EGR1. ${ }^{69}$ Studies show that in neutrophils, lipoxins upregulate the expression of NAB1 and this helps to reduce levels of EGR1 and control inflammation (Figure 2). ${ }^{70}$

Peroxisome proliferator-activated receptor gamma (PPAR $\gamma$ ) is a transcription factor that downregulates inflammation. ${ }^{71}$ The presence of lipoxins has been shown to increase the levels of PPAR $\gamma$ and neutrophil gelatinaseassociated lipocalin (NGAL) gene. Chronic inflammation in neonates is related to impairment of lipoxin activity in neutrophils and reduction in expression of PPAR $\gamma .{ }^{72}$ PPAR $\gamma$ binds to target gene NGAL expressed in tissues that are exposed to microorganisms and promotes apoptosis of neutrophils. ${ }^{73}$

Nrf2 is a transcription factor that regulates the expression of antioxidant response element, which is involved in the production of antioxidants and detoxication enzymes. ${ }^{74}$ Nrf2 is highly expressed in activated macrophages, thyroid glands, and detoxification organs such as the liver, kidney, and lungs. ${ }^{75}$ A study has shown that during the resolution stage of inflammation, there is an increased amount of 15-deoxy prostaglandin J2 (15-dPGJ2) found at the site of inflammation. ${ }^{76}$ A study by Itoh et al has shown that $15-\mathrm{dPGJ} 2$ inhibits the nuclear accumulation of NFKB and AP-1, activates PPAR $\gamma$ to regulate pro-inflammatory pathways, and also activates $\mathrm{Nrf} 2$. Activated Nrf 2 inhibits TNF $\alpha$ mediated induction of vascular cell adhesion molecule-1, which is important for recruitment of monocytes to the site of inflammation. ${ }^{77}$ Lipoxins play an important role in resolving inflammation by activating $\mathrm{Nrf} 2$ and delaying apoptosis of macrophages. ${ }^{59}$

\section{Lipoxins and their clinical relevance}

This section presents a discussion on the clinical relevance of lipoxins, particularly related to inflammation occurring in renal diseases, respiratory tract, cancer, neurodegenerative diseases, and viral infections.

\section{Renal diseases and inflammation}

Kidneys are involved in clearing waste from the blood, hence they receive a high volume of blood to purify. When the kidney encounters pathogens, there is increased infiltration of leukocytes followed by inflammation. ${ }^{78}$ If kidney injury and inflammation is not resolved in a timely manner, then it leads to chronic kidney disease and ultimately end stage renal failure. ${ }^{79}$ Lipoxins inhibit neutrophil infiltration in the kidneys and limits tissue damage. ${ }^{80}$

Kidney fibrosis is a common manifestation of chronic kidney disease. ${ }^{81}$ Transforming growth factor (TGF) $\beta 1$ induces fibrotic conditions of the kidneys by downregulating let-7c miRNA. When epithelial cells are pretreated with lipoxin, an increase in the level of let-7c miRNA is observed. let-7c miRNA targets TGF $\beta$ Receptor 1, a vital component of TGF $\beta 1$ signaling which is upregulated in renal fibrosis. ${ }^{82}$

Lipoxins and epi-lipoxins have been shown to be effective in treating acute renal failure mouse model. ${ }^{83}$ Renal failure mice when treated with lipoxins have an increased level of mRNA suppressors of cytokine signaling (SOCS-1, 2). ${ }^{84}$ SOCS bind to Janus kinase and other cytokine receptors to suppress cytokine action and reduce inflammation. ${ }^{85}$ Together, these studies support the concept of treating kidney-related inflammation by lipoxins.

\section{Cancer and inflammation}

The first relationship between inflammation and cancer was proposed by Rudolf Virchow in 1863. Today, approximately $15 \%$ of global cancer is due to infection and inflammation. Tumors have large quantities of vascular endothelial growth factors (VEGF) ${ }^{86}$ and $\mathrm{TNF},{ }^{87}$ which in turn promote several angiogenic factors essential for tumor formation. Lipoxin and ATL A4 treatment of a cancer-induced bone pain model has shown a reduction in mRNA expression of the proinflammatory cytokines like IL- $1 \beta$ and TNF- $\alpha .{ }^{88}$ Studies using non-steroidal anti-inflammatory drugs on animal tumor models and human subjects have shown promising results in 
reduction of tumor growth and death due to digestive tract cancers. ${ }^{89,90}$ Cancer cells expressing high levels of COX-2 produce epi-lipoxins in response to aspirin. ${ }^{91,92}$ Epi-lipoxin has been shown to inhibit VEGF-stimulated endothelial cell migration in tumors by reducing its angiogenicity. ${ }^{93}$ Pancreatic ductal adenocarcinoma (PDAC) is a malignancy of the pancreas that is often diagnosed in the terminal stages and is the fourth leading cause of cancer. ${ }^{44,94,95}$ A combination of several chemotherapeutic agents is currently used in treatment of PDAC, but unfortunately they have significant side effects, even though increasing life expectancy by 6 months. ${ }^{96,97}$ Hence, there is a need to find other targets to treat PDAC. Transcriptional factors like nuclear factor of activated T-cells, Nrf2, and NFאB have been recently identified as potential targets to cure PDAC. ${ }^{98}$ Lipoxins have been shown to downregulate Nrf2 and NFKB expression and could be used as a potential treatment for colon and pancreatic cancers. ${ }^{99}$ Several studies show that regular aspirin use reduces the risk of cancer. ${ }^{91,92}$ Since lipoxins can target variety of inflammatory and angiogenic molecules, it could be potentially used in a combination therapy along with anticancer drugs to treat cancer. Further studies are required to see whether lipoxins could be used as a drug in preventing cancer. So far, clinical trials have shown that regular dose of aspirin ( $325 \mathrm{mg} /$ day) can provide protection against colorectal cancer. ${ }^{100}$

\section{Respiratory tract diseases and inflammation}

Asthma is a common airway obstruction inflammatory disease caused by defective arachidonic acid metabolism. ${ }^{101,102}$ Study on an asthma animal model has found that lipoxin secretion is decreased due to oxidative stress and soluble epoxide hydrolase activity. ${ }^{103}$ Administering epi-lipoxin to asthma models has shown a significant decrease in airway hyper-responsiveness and inflammation. ${ }^{104}$ Besides asthma, chronic obstructive pulmonary disease is another airway inflammation disease associated with long-term exposure of the lungs to irritants like cigarette smoke and other pollutants found in the air. In chronic obstructive pulmonary disease, there is an overexpression of $\mathrm{C}$ reactive protein and SAA. ${ }^{105} \mathrm{C}$ reactive protein and SAA bind to ALX to promote inflammation and inhibit lipoxin signaling. ${ }^{106}$ If lipoxins are present in sufficient amounts, then it can prevent SAA binding to ALX/FPR2, thereby aiding in resolving the inflammation. ${ }^{107}$

The severe asthma research program 3 is currently conducting a clinical trial at Boston Children's Hospital and Brigham and Women's Hospital to understand how corticosteroids used in treatment of asthma affect lipoxin production.

\section{Neurodegenerative diseases}

Alzheimer's disease, a neurodegenerative disorder, is characterized by the accumulation of amyloid plaques, inflammatory cytokines, and other neurotoxic substances. ${ }^{87}$ The microglial cells that function in the brain to phagocytize the amyloid plaques and prevent its accumulation are affected in Alzheimer's disease. ${ }^{108}$ An Alzheimer's disease animal model when treated with epi-lipoxin showed a reduction in $\mathrm{NF \kappa B}$ and inflammatory cytokine levels along with an increase in anti-inflammatory cytokine IL-10 and TGF $\beta$. This change in the inflammatory environment helps to recruit microglial cells in an alternative phenotype to enhance its phagocytic ability. ${ }^{109}$ Apart from their anti-inflammatory effect, they are also found to be neuroprotective in animal studies performed on middle cerebral occlusion mice (common model of cerebral injury). Pro-inflammatory mediators like 5-LO and leukotrienes are upregulated in cerebral ischemia. ${ }^{110}$ The subcellular location of 5-LO determines the amount of leukotriene secretion. Serine phosphorylation of 5-LO helps its movement into the nucleus where it increases secretion of leukotriene B4. ${ }^{111}$ Study on a mid-cerebral artery occlusion animal model has shown that administering lipoxins prevented nuclear translocation of 5-LO and inhibited upregulation of leukotriene B4 and C4. ${ }^{112}$

Traumatic brain injury causes disruption of the bloodbrain barrier and inflammation, which could potentially lead to death. Lipoxin treatment in a traumatic brain injury model has been found to reduce blood-brain barrier breakdown and lesion volume. Lipoxins inhibit activation of the ERK and Jun-N terminal kinase pathways and control inflammation by downregulating secretion of pro-inflammatory cytokines like TNF $\alpha$, IL-1 $\beta$ and IL- $6 .{ }^{113}$ These studies highlight the potential of using lipoxins in treatment of neurodegenerative diseases affecting brain and spinal cord.

\section{Viral infections}

The H5NI influenza virus causes a severe immune response in humans. ${ }^{114}$ Influenza virus H5NI causes a sustained inflammatory response and inhibition of lipoxin-mediated anti-inflammatory responses. Two main anti-inflammatory genes: arachidonate 5-Lipoxygenase (ALOX5), a gene responsible for lipoxin synthesis, and a gene encoding SOCS-2 were downregulated upon viral infection. On the other hand, several genes involved in the pro-inflammatory 
cytokines like TNF $\alpha$ and interferon- $\gamma$ were found to be upregulated. ${ }^{115}$ Further studies are required to understand the influence of anti-inflammatory lipoxin pathway and H5N1 pathogenesis.

Respiratory syncytial virus causes lower respiratory tract infection by infecting lung macrophages and epithelial cells. ${ }^{116,117}$ There are two types of macrophages that play an important role during respiratory syncytial virus infection - classically activated macrophages and alternatively activated macrophages. During initial stages of infection, classically activated macrophages stimulate production of pro-inflammatory COX-2. ${ }^{118}$ During later stages of infection, there is resolution of inflammation by stimulation of alternatively activated macrophages that counteract with initially stimulated pro-inflammatory response by inducing anti-inflammatory cytokines like IL-10, lipoxin, and resolvins. ${ }^{119}$ A study shows that when anti-inflammatory LO pathway is activated, they promote differentiation of alternatively activated macrophages and help resolve airway hyper reactivity. Shutting down COX-2 pathway has been proposed as a mechanism to promote LO activity and resolve lung pathogenesis. ${ }^{118,120}$

Epstein-Bar virus (EBV) is a human herpes virus that has been detected in various lymphomas, ${ }^{121-123}$ typically in the latent phase. ${ }^{124}$ Switching from the latent to lytic cycle leads to the destruction of tumor cells, and also triggers the immune response. ${ }^{125} \mathrm{NF \kappa B}$, a transcription factor that plays an important role in inflammation, is constitutively activated in several types of cancers. ${ }^{126,127}$ Latent membrane proteins coded by EBV suppress the lytic cycle ${ }^{128}$ and also upregulates the expression of NFKB. ${ }^{129-132}$ A study shows that aspirin treatment on EBV-positive lymphoma decreased nuclear translocation of NFKB and promotes the lytic cycle. Aspirin could be used in combination with other anticancer drugs to effectively treat EBV-positive lymphomas. ${ }^{133}$

Another human herpes virus called Kaposi's sarcomaassociated herpes virus (KSHV) is a gamma herpes virus associated with Kaposi's sarcoma (KS), primary effusion lymphoma (PEL), and multicentric Castleman's disease. ${ }^{134-138}$ Constitutive activation of NFאB has been seen in KSHVinfected PEL cells when compared with uninfected B-cell lymphoma cells. NFא $\beta$ has been shown to be essential for the survival and proliferation of $\mathrm{KSHV}$; therefore, $\mathrm{NF} \kappa \beta$ inhibitors are important for the treatment of KS and PEL. ${ }^{139,140}$ $\mathrm{NF} \kappa \mathrm{B}$ inhibitors belong to three functional categories: inhibiting proteasomal degradation of $\mathrm{I} \kappa \mathrm{B}$, inhibiting phosphorylation of $\mathrm{I} \kappa \mathrm{B}$, and inhibiting $\mathrm{NF} \kappa \mathrm{B}$ translocation into the nucleus. Aspirin is a NFאB inhibitor, which blocks phosphorylation of I $\kappa$ B. A study using the I $\beta \beta$ phosphorylation inhibitor Bay11-7082 has shown promising results in apoptosis of KSHV-infected cells. ${ }^{139,140}$ This suggests the potential use of NFKB inhibitors for the treatment of KS. ${ }^{139}$

Multiple studies have shown that pro-inflammatory pathways are upregulated upon KSHV infection. ${ }^{141-149} \mathrm{KS}$ cells show a marked increase in inflammatory proteins like COX-2, Prostaglandin E2, and 5-LO. ${ }^{141-149}$ Our previous studies show that the use of COX-2 inhibitors helps target PEL and ameliorate KS pathogenesis of KS. ${ }^{141-149}$

A recent study from our lab showed that lipoxins have an anti-inflammatory and anti-angiogenic role in KS cells. ${ }^{150}$ Angiogenesis is a hallmark of cancer. ${ }^{151}$ VEGF and its receptor play a major role in regulating angiogenesis. VEGF and its receptor (VEGFR) interactions have been shown to promote KS pathogenesis. ${ }^{152-155}$ There are four different VEGFs: A, B, C, and D plus three types of VEGFR: 1, 2, and 3. VEGF is produced by fibroblasts, endothelial cells, and several inflammatory cells. ${ }^{156}$ Elevated levels of VEGF mRNA are seen in many tumor models, arthritis, and inflammatory conditions. ${ }^{157}$ Lipoxins were shown to have the potential to regulate angiogenesis by downregulating VEGF-C secretion and modulating VEGF-VEGFR interactions in KS cells. ${ }^{150}$ Phosphorylation of VEGFR2 at Y951, Y1059, Y1175, and Y1212 is important in regulating the VEGF-VEGFR signaling cascade. ${ }^{158-160}$ Treatment of KS cells with lipoxins showed a decrease in phosphorylation of VEGFR2 at sites noted above. ${ }^{150}$ Lipoxin treatment of KS-IMM cells shifts an inflammatory environment to more of anti-inflammatory and resolving environment. Lipoxin treatment in virus-infected cells shows a decreased secretion of pro-inflammatory cytokines IL-6 and IL-8 and increased secretion of IL-10. IL-6 is an important growth factor for KSHV pathogenesis, and increased levels of IL-6 transcription were found during the initial stages of infection. ${ }^{161}$ IL-8 acts as a chemoattractant and can enhance endothelial cell survival and proliferation, while also regulating angiogenesis. ${ }^{162}$

Current treatments for KS and PEL rely on systemic chemotherapeutics developed for non-virus associated cancers that target DNA replication of all dividing cells. Other treatment methods aim at keeping the immune system healthy and controlling the infection through surgery. All the above approaches have low efficacy, high cost, and a serious risk of secondary malignancies, especially in immunocompromised patients. ${ }^{163-165}$ Though in vitro studies using COX-2 inhibitors were encouraging, these inhibitors are also associated with increased risk of thrombotic and cardiovascular issues. ${ }^{166}$ Hence, there is an emerging need to look for alternative 
treatment options for KS. Therapeutic potential of lipoxins in KS shows a promising future but are yet to be explored. The studies discussed earlier in this section pave the way for future studies exploring role of lipoxins in KSHV biology. Unpublished results from our laboratory show that upon virus infection there is a decrease in lipoxin secretion from the infected cells. The decrease in lipoxin secretion was found to be due to KSHV micro-RNA cluster silencing LO enzymes. Further studies need to be performed to understand how lipoxin alters KSHV life cycle. Lipoxins in clinical treatment of virus-induced inflammation is yet to be studied.

\section{Conclusion}

Effective resolution of inflammation is essential to restore the host cells and tissues to its natural form. Anti-inflammatory, anti-proliferative, and pro-resolving molecules like lipoxins are essential in maintaining tissue homeostasis. Lipoxins were discovered almost four decades ago and yet their potential application as a drug to treat inflammatory diseases has not reached clinical stage. More specifically, drugs like aspirin which can trigger anti-inflammatory lipoxin synthesis, would have more broad applications in the future than the currently used anti-inflammatory drugs. Studies in animal models show that inflammation-related conditions of renal failure and respiratory tract diseases like asthma could be brought under control by treatment with lipoxins. The relationship between inflammation and cancer is well established and regular use of aspirin in cancer patients has shown promising results. As in the case of any drug, aspirin also has a physiological limit that should not be exceeded. Overdose of aspirin has been linked with increased risk of allergy, stomach ulcers, and profuse bleeding. ${ }^{167}$ More studies are required to assess the safety and efficacy profile of lipoxins. The major challenge in using lipoxins and ATL in clinical trial is their chemical instability in acid and light along with shorter half-life. Development of stable analogs is still under research. Currently, BLXA4, a lipoxin analog, is in clinical trial phase 1 for treating oral gingivitis. Bayer HealthCare is working on two lipoxin analogs ZK-142 and ZK-994 and have demonstrated anti-inflammatory effectiveness in various animal models. ${ }^{90,168}$ University of Southern California has developed and patented a stable analog of lipoxin, Benzo-lipoxin, and is currently studying its use in treating inflammatory diseases. The use of lipoxins or epilipoxins in treating viral infections and inflammation is yet to be explored and warrant attention. In short, lipoxins could be a commercially successful drug as they have a potential to target a lot of pro-inflammatory pathways like COX-2, NFкB, AP-1, and VEGF, which are upregulated in various diseases.

\section{Acknowledgments}

We gratefully acknowledge Professor Bala Chandran and Keith Philibert for suggestions and critically reading the manuscript. The authors are grateful to Rosalind Franklin University of Medicine and Science start-up funds, Schweppe scholar award, and the American Cancer Society-Illinois grant (279196) for the support of their work related to this topic.

\section{Disclosure}

The authors report no conflicts of interest in this work.

\section{References}

1. Serhan CN, Savill J. Resolution of inflammation: the beginning programs the end. Nat Immunol. 2005;6(12):1191-1197.

2. Fierro IM, Serhan CN. Mechanisms in anti-inflammation and resolution: the role of lipoxins and aspirin-triggered lipoxins. Braz J Med Biol Res. 2001;34(5):555-566.

3. Serhan CN, Hamberg M, Samuelsson B. Lipoxins: novel series of biologically active compounds formed from arachidonic acid in human leukocytes. Proc Natl Acad Sci U S A. 1984;81(17):5335-5339.

4. Hamberg M, Samuelsson B. Prostaglandin endoperoxides. Novel transformations of arachidonic acid in human platelets. Proc Natl Acad Sci U S A 1974;71(9):3400-3404.

5. Malhotra S, Deshmukh SS, Dastidar SG. COX inhibitors for airway inflammation. Expert Opin Ther Targets. 2012;16(2):195-207.

6. Serhan CN, Sheppard KA. Lipoxin formation during human neutrophilplatelet interactions. Evidence for the transformation of leukotriene $\mathrm{A} 4$ by platelet 12-lipoxygenase in vitro. J Clin Invest. 1990;85(3): 772-780.

7. Claria J, Serhan CN. Aspirin triggers previously undescribed bioactive eicosanoids by human endothelial cell-leukocyte interactions. Proc Natl Acad Sci U S A. 1995;92(21):9475-9479.

8. Cheng TI, Cheng TJ, Chiang SC. Association of aspirin with eosinophilia in peripheral blood. Ann Pharmacother. 2004;38(12):2172-2173.

9. Chiang N, Serhan CN. Aspirin triggers formation of anti-inflammatory mediators: new mechanism for an old drug. Discov Med. 2004;4(24):470-475.

10. Fan SY, Zeng HW, Pei YH, et al. The anti-inflammatory activities of an extract and compounds isolated from Platycladus orientalis (Linnaeus) Franco in vitro and ex vivo. J Ethnopharmacol. 2012;141(2): 647-652.

11. Chiang N, Hurwitz S, Ridker PM, Serhan CN. Aspirin has a gender-dependent impact on antiinflammatory 15-epi-lipoxin A4 formation: a randomized human trial. Arterioscler Thromb Vasc Biol. 2006;26(2):e14-e17.

12. Russell R, Gori I, Pellegrini C, Kumar R, Achtari C, Canny GO. Lipoxin A4 is a novel estrogen receptor modulator. FASEB J. 2011;25(12): 4326-4337.

13. Canny GO, Lessey BA. The role of lipoxin A4 in endometrial biology and endometriosis. Mucosal Immunol. 2013;6(3):439-450.

14. Birnbaum Y, Ye Y, Lin Y, et al. Augmentation of myocardial production of 15-epi-lipoxin-a4 by pioglitazone and atorvastatin in the rat. Circulation. 2006;114(9):929-935.

15. Planaguma A, Pfeffer MA, Rubin G, et al. Lovastatin decreases acute mucosal inflammation via 15-epi-lipoxin A4. Mucosal Immunol. 2010;3(3):270-279.

16. Levy BD. Myocardial 15-epi-lipoxin A4 generation provides a new mechanism for the immunomodulatory effects of statins and thiazolidinediones. Circulation. 2006;114(9):873-875.

17. Serhan CN, Levy BD, Clish CB, Gronert K, Chiang N. Lipoxins, aspirin-triggered 15-epi-lipoxin stable analogs and their receptors in anti-inflammation: a window for therapeutic opportunity. Ernst Schering Res Found Workshop. 2000(31):143-185. 
18. Schaldach CM, Riby J, Bjeldanes LF. Lipoxin A4: a new class of ligand for the Ah receptor. Biochemistry. 1999;38(23):7594-7600.

19. Gronert K, Martinsson-Niskanen T, Ravasi S, Chiang N, Serhan CN. Selectivity of recombinant human leukotriene $\mathrm{D}(4)$, leukotriene $\mathrm{B}(4)$, and lipoxin $\mathrm{A}(4)$ receptors with aspirin-triggered 15-epi-LXA(4) and regulation of vascular and inflammatory responses. Am J Pathol. 2001;158(1):3-9.

20. Papayianni A, Serhan CN, Phillips ML, Rennke HG, Brady HR. Transcellular biosynthesis of lipoxin A4 during adhesion of platelets and neutrophils in experimental immune complex glomerulonephritis. Kidney Int. 1995;47(5):1295-1302.

21. Chiang N, Bermudez EA, Ridker PM, Hurwitz S, Serhan CN. Aspirin triggers antiinflammatory 15 -epi-lipoxin $\mathrm{A} 4$ and inhibits thromboxane in a randomized human trial. Proc Natl Acad Sci U S A. 2004;101(42): 15178-15183.

22. Ridker PM, Cook NR, Lee IM, et al. A randomized trial of low-dose aspirin in the primary prevention of cardiovascular disease in women. N Engl J Med. 2005;352(13):1293-1304.

23. Rothberg MB, Celestin C, Fiore LD, Lawler E, Cook JR. Warfarin plus aspirin after myocardial infarction or the acute coronary syndrome: meta-analysis with estimates of risk and benefit. Ann Intern Med. 2005;143(4):241-250.

24. Cook NR, Lee IM, Gaziano JM, et al. Low-dose aspirin in the primary prevention of cancer: the Women's Health Study: a randomized controlled trial. JAMA. 2005;294(1):47-55.

25. Giovannucci E, Egan KM, Hunter DJ, et al. Aspirin and the risk of colorectal cancer in women. $N$ Engl J Med. 1995;333(10):609-614.

26. Yin H, Liu W, Goleniewska K, Porter NA, Morrow JD, Peebles RS Jr. Dietary supplementation of omega-3 fatty acid-containing fish oil suppresses F2-isoprostanes but enhances inflammatory cytokine response in a mouse model of ovalbumin-induced allergic lung inflammation. Free Radic Biol Med. 2009;47(5):622-628.

27. Isakson P, Seibert K, Masferrer J, Salvemini D, Lee L, Needleman P Discovery of a better aspirin. Adv Prostaglandin Thromboxane Leukot Res. 1995;23:49-54.

28. Chiang N, Takano T, Clish CB, Petasis NA, Tai HH, Serhan CN. Aspirin-triggered 15-epi-lipoxin A4 (ATL) generation by human leukocytes and murine peritonitis exudates: development of a specific 15-epi-LXA4 ELISA. J Pharmacol Exp Ther. 1998;287(2):779-790.

29. Schottelius AJ, Giesen C, Asadullah K, et al. An aspirin-triggered lipoxin A4 stable analog displays a unique topical anti-inflammatory profile. J Immunol. 2002;169(12):7063-7070.

30. Serhan CN. Eicosanoids in leukocyte function. Curr Opin Hematol. 1994;1(1):69-77.

31. Serhan CN. Lipoxins and novel aspirin-triggered 15-epi-lipoxins (ATL): a jungle of cell-cell interactions or a therapeutic opportunity? Prostaglandins. 1997;53(2):107-137.

32. Serhan CN. Lipoxin metabolism by human promyelocytic leukemia (HL-60) cells. Adv Exp Med Biol. 1997;400B:641-646.

33. Serhan CN. Systems approach with inflammatory exudates uncovers novel anti-inflammatory and pro-resolving mediators. Prostaglandins Leukot Essent Fatty Acids. 2008;79(3-5):157-163.

34. Serhan CN, Chiang N. Novel endogenous small molecules as the checkpoint controllers in inflammation and resolution: entree for resoleomics. Rheum Dis Clin North Am. 2004;30(1):69-95.

35. Serhan CN, Chiang N. Endogenous pro-resolving and anti-inflammatory lipid mediators: a new pharmacologic genus. Br J Pharmacol. 2008; 153(Suppl 1):S200-S215.

36. Serhan CN, Chiang N, Van Dyke TE. Resolving inflammation: dual anti-inflammatory and pro-resolution lipid mediators. Nat Rev Immunol. 2008;8(5):349-361.

37. Serhan CN, Fierro IM, Chiang N, Pouliot M. Cutting edge: nociceptin stimulates neutrophil chemotaxis and recruitment: inhibition by aspirintriggered-15-epi-lipoxin A4. J Immunol. 2001;166(6):3650-3654

38. Baker N, O’Meara SJ, Scannell M, Maderna P, Godson C. Lipoxin A4: anti-inflammatory and anti-angiogenic impact on endothelial cells. J Immunol. 2009;182(6):3819-3826.
39. Maderna P, Cottell DC, Toivonen T, et al. FPR2/ALX receptor expression and internalization are critical for lipoxin A4 and annexin-derived peptide-stimulated phagocytosis. FASEB J. 2010;24(11):4240-4249.

40. Mitchell S, Thomas G, Harvey K, et al. Lipoxins, aspirin-triggered epi-lipoxins, lipoxin stable analogues, and the resolution of inflammation: stimulation of macrophage phagocytosis of apoptotic neutrophils in vivo. J Am Soc Nephrol. 2002;13(10):2497-2507.

41. Dirix CE, Hogervorst JG, Rump P, Hendriks JJ, Bruins M, Hornstra G. Prenatal arachidonic acid exposure and selected immune-related variables in childhood. Br J Nutr. 2009;102(3):387-397.

42. Radmark O, Samuelsson B. 5-Lipoxygenase: mechanisms of regulation. J Lipid Res. 2009;50(Supp1):S40-S45.

43. O’Bryan L, Pinkston P, Kumaraswami V, et al. Localized eosinophil degranulation mediates disease in tropical pulmonary eosinophilia. Infect Immun. 2003;71(3):1337-1342.

44. Luscinskas FW, Nicolaou KC, Webber SE, Veale CA, Gimbrone MA Jr, Serhan CN. Ca2+ mobilization with leukotriene A4 and epoxytetraenes in human neutrophils. Biochem Pharmacol. 1990;39(2): $355-365$.

45. Dixit N, Simon SI. Chemokines, selectins and intracellular calcium flux: temporal and spatial cues for leukocyte arrest. Front Immunol. 2012;3:188.

46. Weiss SJ. Tissue destruction by neutrophils. N Engl J Med. 1989;320(6): 365-376.

47. Matute-Bello G, Liles WC, Radella F 2nd, et al. Neutrophil apoptosis in the acute respiratory distress syndrome. Am J Respir Crit Care Med. 1997;156(6):1969-1977.

48. Andzinski L, Wu CF, Lienenklaus S, Kroger A, Weiss S, Jablonska J. Delayed apoptosis of tumor associated neutrophils in the absence of endogenous IFN-beta. Int $J$ Cancer. 2015;136(3):572-583.

49. El Kebir D, Jozsef L, Pan W, Filep JG. Myeloperoxidase delays neutrophil apoptosis through CD11b/CD18 integrins and prolongs inflammation. Circ Res. 2008;103(4):352-359.

50. Klebanoff SJ. Myeloperoxidase: friend and foe. J Leukoc Biol. 2005;77(5):598-625.

51. El Kebir D, Jozsef L, Pan W, et al. 15-epi-lipoxin A4 inhibits myeloperoxidase signaling and enhances resolution of acute lung injury. Am J Respir Crit Care Med. 2009;180(4):311-319.

52. El Kebir D, Jozsef L, Khreiss T, et al. Aspirin-triggered lipoxins override the apoptosis-delaying action of serum amyloid A in human neutrophils: a novel mechanism for resolution of inflammation. J Immunol. 2007;179(1):616-622.

53. Hooper DC, Scott GS, Zborek A, et al. Uric acid, a peroxynitrite scavenger, inhibits CNS inflammation, blood-CNS barrier permeability changes, and tissue damage in a mouse model of multiple sclerosis. FASEB J. 2000;14(5):691-698.

54. Beckman JS, Beckman TW, Chen J, Marshall PA, Freeman BA. Apparent hydroxyl radical production by peroxynitrite: implications for endothelial injury from nitric oxide and superoxide. Proc Natl Acad Sci U S A. 1990;87(4):1620-1624.

55. Jozsef L, Zouki C, Petasis NA, Serhan CN, Filep JG. Lipoxin A4 and aspirin-triggered 15-epi-lipoxin A4 inhibit peroxynitrite formation, NF-kappa B and AP-1 activation, and IL-8 gene expression in human leukocytes. Proc Natl Acad Sci U S A. 2002;99(20):13266-13271.

56. Zouki C, Jozsef L, Ouellet S, Paquette Y, Filep JG. Peroxynitrite mediates cytokine-induced IL-8 gene expression and production by human leukocytes. J Leukoc Biol. 2001;69(5):815-824.

57. Filep JG, Beauchamp M, Baron C, Paquette Y. Peroxynitrite mediates IL-8 gene expression and production in lipopolysaccharide-stimulated human whole blood. J Immunol. 1998;161(10):5656-5662.

58. Aprile A, Lucarelli S, Vagnucci B, Frediani T. The use of antileukotrienes in paediatrics. Eur Rev Med Pharmacol Sci. 2001;5(2): 53-57.

59. Prieto P, Cuenca J, Traves PG, Fernandez-Velasco M, Martin-Sanz P, Bosca L. Lipoxin A4 impairment of apoptotic signaling in macrophages: implication of the PI3K/Akt and the ERK/Nrf-2 defense pathways. Cell Death Differ. 2010;17(7):1179-1188. 
60. Khatami M. Unresolved inflammation: 'immune tsunami' or erosion of integrity in immune-privileged and immune-responsive tissues and acute and chronic inflammatory diseases or cancer. Expert Opin Biol Ther. 2011;11(11):1419-1432.

61. O'Sullivan S. On the role of PGD2 metabolites as markers of mast cell activation in asthma. Acta Physiol Scand Suppl. 1999;644:1-74.

62. Ramon S, Bancos S, Serhan CN, Phipps RP. Lipoxin A(4) modulates adaptive immunity by decreasing memory B-cell responses via an ALX/ FPR2-dependent mechanism. Eur J Immunol. 2014;44(2):357-369.

63. Ariel A, Chiang N, Arita M, Petasis NA, Serhan CN. Aspirin-triggered lipoxin A4 and B4 analogs block extracellular signal-regulated kinasedependent TNF-alpha secretion from human T cells. J Immunol. 2003;170(12):6266-6272.

64. Levy BD, Fokin VV, Clark JM, Wakelam MJ, Petasis NA, Serhan CN. Polyisoprenyl phosphate (PIPP) signaling regulates phospholipase D activity: a 'stop' signaling switch for aspirin-triggered lipoxin A4. FASEB J. 1999;13(8):903-911.

65. Liu Y, Kach A, Ziegler U, et al. The role of phospholipase D in modulating the MTOR signaling pathway in polycystic kidney disease. PLoS One. 2013;8(8):e73173.

66. Barnes PJ, Karin M. Nuclear factor-kappaB: a pivotal transcription factor in chronic inflammatory diseases. N Engl J Med. 1997;336(15): 1066-1071.

67. Decker EL, Nehmann N, Kampen E, Eibel H, Zipfel PF, Skerka C. Early growth response proteins (EGR) and nuclear factors of activated T cells (NFAT) form heterodimers and regulate proinflammatory cytokine gene expression. Nucleic Acids Res. 2003;31(3):911-921.

68. Parra E, Ferreira J, Ortega A. Overexpression of EGR-1 modulates the activity of NF-kappaB and AP-1 in prostate carcinoma PC-3 and LNCaP cell lines. Int J Oncol. 2011;39(2):345-352.

69. Thiel G, Kaufmann K, Magin A, Lietz M, Bach K, Cramer M. The human transcriptional repressor protein NAB1: expression and biological activity. Biochim Biophys Acta. 2000;1493(3):289-301.

70. Qiu FH, Devchand PR, Wada K, Serhan CN. Aspirin-triggered lipoxin A4 and lipoxin A4 up-regulate transcriptional corepressor NAB1 in human neutrophils. FASEB J. 2001;15(14):2736-2738.

71. Delerive P, De Bosscher K, Besnard S, et al. Peroxisome proliferatoractivated receptor alpha negatively regulates the vascular inflammatory gene response by negative cross-talk with transcription factors NF-kappaB and AP-1. J Biol Chem. 1999;274(45):32048-32054.

72. Weinberger B, Quizon C, Vetrano AM, Archer F, Laskin JD, Laskin DL. Mechanisms mediating reduced responsiveness of neonatal neutrophils to lipoxin A4. Pediatr Res. 2008;64(4):393-398.

73. Kjeldsen L, Cowland JB, Borregaard N. Human neutrophil gelatinaseassociated lipocalin and homologous proteins in rat and mouse. Biochim Biophys Acta. 2000;1482(1-2):272-283.

74. Hirst SJ, Lee TH. Airway smooth muscle as a target of glucocorticoid action in the treatment of asthma. Am J Respir Crit Care Med. 1998;158 (5 Pt 3):S201-S206.

75. van der Velden VH. Glucocorticoids: mechanisms of action and antiinflammatory potential in asthma. Mediators Inflamm. 1998;7(4): 229-237.

76. Nagai H, Tanaka H. [The role of cytokines and arachidonic acid metabolites in the development of airway hyperresponsiveness]. Nihon Yakurigaku Zasshi. 1998;111(4):233-241. Japanese.

77. Itoh K, Mochizuki M, Ishii Y, et al. Transcription factor Nrf2 regulates inflammation by mediating the effect of 15-deoxy-Delta(12,14)prostaglandin j(2). Mol Cell Biol. 2004;24(1):36-45.

78. Medina Avalos MA, Orea Solano M. [Macrophages in asthma]. Rev Alerg Mex. 1997;44(5):135-139.

79. Borgeson E, Godson C. Molecular circuits of resolution in renal disease. Scientific World Journal. 2010;10:1370-1385

80. Maderna P, Godson C. Lipoxins: resolutionary road. Br J Pharmacol. 2009;158(4):947-959.

81. Bochner BS, Undem BJ, Lichtenstein LM. Immunological aspects of allergic asthma. Annu Rev Immunol. 1994;12:295-335.

82. Brennan EP, Nolan KA, Borgeson E, et al. Lipoxins attenuate renal fibrosis by inducing let-7c and suppressing TGFbetaR1. J Am Soc Nephrol. 2013;24(4):627-637.
83. Kieran NE, Doran PP, Connolly SB, et al. Modification of the transcriptomic response to renal ischemia/reperfusion injury by lipoxin analog. Kidney Int. 2003;64(2):480-492.

84. Machado FS, Johndrow JE, Esper L, et al. Anti-inflammatory actions of lipoxin A4 and aspirin-triggered lipoxin are SOCS-2 dependent. Nat Med. 2006;12(3):330-334.

85. Yoshimura A, Suzuki M, Sakaguchi R, Hanada T, Yasukawa H. SOCS, inflammation, and autoimmunity. Front Immunol. 2012;3:20.

86. Underner M, Boita F, Patte F. [Mode of action of corticoids in asthma]. Rev Pneumol Clin. 1986;42(4):173-182.

87. Querfurth HW, LaFerla FM. Alzheimer's disease. N Engl J Med. 2010; 362(4):329-344.

88. Hu S, Mao-Ying QL, Wang J, et al. Lipoxins and aspirin-triggered lipoxin alleviate bone cancer pain in association with suppressing expression of spinal proinflammatory cytokines. J Neuroinflammation. 2012;9:278.

89. Guerrero-Plata A, Ortega E, Gomez B. Persistence of respiratory syncytial virus in macrophages alters phagocytosis and pro-inflammatory cytokine production. Viral Immunol. 2001;14(1):19-30.

90. Bannenberg G, Moussignac RL, Gronert K, et al. Lipoxins and novel 15-epi-lipoxin analogs display potent anti-inflammatory actions after oral administration. Br J Pharmacol. 2004;143(1):43-52.

91. Claria J. Regulation of cell proliferation and apoptosis by bioactive lipid mediators. Recent Pat Anticancer Drug Discov. 2006;1(3):369-382.

92. Claria J, Romano M. Pharmacological intervention of cyclooxygenase-2 and 5-lipoxygenase pathways. Impact on inflammation and cancer. Curr Pharm Des. 2005;11(26):3431-3447.

93. Vieira AM, Neto EH, Figueiredo CC, Barja Fidalgo C, Fierro IM, Morandi V. ATL-1, a synthetic analog of lipoxin, modulates endothelial permeability and interaction with tumor cells through a VEGFdependent mechanism. Biochem Pharmacol. 2014;90(4):388-396.

94. Ding C, Yan J. Regulation of autoreactive B cells: checkpoints and activation. Arch Immunol Ther Exp. 2007;55(2):83-89.

95. Yi Z, Bishop GA. Regulatory role of CD40 in obesity-induced insulin resistance. Adipocyte. 2015;4(1):65-69.

96. Ratikan JA, Micewicz ED, Xie MW, Schaue D. Radiation takes its Toll. Cancer Lett. 2015.

97. Liu G, Abraham E. MicroRNAs in immune response and macrophage polarization. Arterioscler Thromb Vasc Biol. 2013;33(2):170-177.

98. Arlt A, Schafer H, Kalthoff $\mathrm{H}$. The 'N-factors' in pancreatic cancer: functional relevance of NF-kappaB, NFAT and Nrf2 in pancreatic cancer. Oncogenesis. 2012;1:e35.

99. Janakiram NB, Mohammed A, Rao CV. Role of lipoxins, resolvins, and other bioactive lipids in colon and pancreatic cancer. Cancer Metastasis Rev. 2011;30(3-4):507-523.

100. Garcia-Albeniz X, Chan AT. Aspirin for the prevention of colorectal cancer. Best practice and research. Clin Gastroenterol. 2011;25(4-5): 461-472.

101. Wenzel SE. Arachidonic acid metabolites: mediators of inflammation in asthma. Pharmacotherapy. 1997;17(1 Pt 2):3S-12S.

102. Lewis RA, Robin JL. Arachidonic acid derivatives as mediators of asthma. J Allergy Clin Immunol. 1985;76(2 Pt 2):259-264.

103. Ono E, Dutile S, Kazani S, et al. Lipoxin generation is related to soluble epoxide hydrolase activity in severe asthma. Am J Respir Crit Care Med. 2014;190(8):886-897.

104. Levy BD, Serhan CN. Exploring new approaches to the treatment of asthma: potential roles for lipoxins and aspirin-triggered lipid mediators. Drugs Today (Barc). 2003;39(5):373-384.

105. Lopez-Campos JL, Calero C, Rojano B, et al. C-reactive protein and serum amyloid a overexpression in lung tissues of chronic obstructive pulmonary disease patients: a case-control study. Int J Med Sci. 2013;10(8):938-947.

106. Bozinovski S, Uddin M, Vlahos R, et al. Serum amyloid A opposes lipoxin A(4) to mediate glucocorticoid refractory lung inflammation in chronic obstructive pulmonary disease. Proc Natl Acad Sci USA. 2012;109(3):935-940.

107. Levy BD, Serhan CN. Resolution of acute inflammation in the lung. Annu Rev Physiol. 2014;76:467-492. 
108. Solito E, Sastre M. Microglia function in Alzheimer's disease. Front Pharmacol. 2012;3:14.

109. Medeiros R, Kitazawa M, Passos GF, et al. Aspirin-triggered lipoxin A4 stimulates alternative activation of microglia and reduces Alzheimer disease-like pathology in mice. Am J Pathol. 2013;182(5): $1780-1789$

110. Moskowitz MA, Kiwak KJ, Hekimian K, Levine L. Synthesis of compounds with properties of leukotrienes $\mathrm{C} 4$ and D4 in gerbil brains after ischemia and reperfusion. Science. 25 1984;224(4651): 886-889.

111. Flamand N, Luo M, Peters-Golden M, Brock TG. Phosphorylation of serine 271 on 5-lipoxygenase and its role in nuclear export. $J$ Biol Chem. 2009;284(1):306-313.

112. Wu L, Miao S, Zou LB, et al. Lipoxin A4 inhibits 5-lipoxygenase translocation and leukotrienes biosynthesis to exert a neuroprotective effect in cerebral ischemia/reperfusion injury. $J$ Mol Neurosci. 2012;48(1): 185-200.

113. Luo CL, Li QQ, Chen XP, et al. Lipoxin A4 attenuates brain damage and downregulates the production of pro-inflammatory cytokines and phosphorylated mitogen-activated protein kinases in a mouse model of traumatic brain injury. Brain Res. 2013;1502:1-10.

114. de Jong MD. H5N1 transmission and disease: observations from the frontlines. Pediatr Infect Dis J. 2008;27(10 Suppl):S54-S56.

115. Cilloniz C, Pantin-Jackwood MJ, Ni C, et al. Lethal dissemination of $\mathrm{H} 5 \mathrm{~N} 1$ influenza virus is associated with dysregulation of inflammation and lipoxin signaling in a mouse model of infection. $J$ Virol. 2010;84(15):7613-7624.

116. Rivera-Toledo E, Gomez B. Respiratory syncytial virus persistence in macrophages alters the profile of cellular gene expression. Viruses. 2012;4(12):3270-3280.

117. Zhang L, Peeples ME, Boucher RC, Collins PL, Pickles RJ. Respiratory syncytial virus infection of human airway epithelial cells is polarized, specific to ciliated cells, and without obvious cytopathology. $J$ Virol. 2002;76(11):5654-5666.

118. Richardson JY, Ottolini MG, Pletneva L, et al. Respiratory syncytial virus (RSV) infection induces cyclooxygenase 2 : a potential target for RSV therapy. J Immunol. 2005;174(7):4356-4364.

119. Shirey KA, Pletneva LM, Puche AC, et al. Control of RSV-induced lung injury by alternatively activated macrophages is IL-4R alpha-, TLR4-, and IFN-beta-dependent. Mucosal Immunol. 2010;3(3):291-300.

120. Shirey KA, Lai W, Pletneva LM, et al. Role of the lipoxygenase pathway in RSV-induced alternatively activated macrophages leading to resolution of lung pathology. Mucosal Immun. 2014;7(3):549-557.

121. Sugawara Y, Makuuchi M, Takada K. Detection of Epstein-Barr virus DNA in hepatocellular carcinoma tissues from hepatitis C-positive patients. Scand J Gastroenterol. 2000;35(9):981-984.

122. Sugawara Y, Mizugaki Y, Uchida T, et al. Detection of Epstein-Barr virus (EBV) in hepatocellular carcinoma tissue: a novel EBV latency characterized by the absence of EBV-encoded small RNA expression. Virology. 1999;256(2):196-202.

123. Harabuchi Y, Yamanaka N, Kataura A, et al. Epstein-Barr virus in nasal T-cell lymphomas in patients with lethal midline granuloma. Lancet. 1990;335(8682):128-130.

124. Young LS, Rickinson AB. Epstein-Barr virus: 40 years on. Nat Rev Cancer. 2004;4(10):757-768.

125. Westphal EM, Blackstock W, Feng W, Israel B, Kenney SC. Activation of lytic Epstein-Barr virus (EBV) infection by radiation and sodium butyrate in vitro and in vivo: a potential method for treating EBVpositive malignancies. Cancer Res. 2000;60(20):5781-5788.

126. Shukla S, MacLennan GT, Fu P, et al. Nuclear factor-kappaB/p65 (Rel A) is constitutively activated in human prostate adenocarcinoma and correlates with disease progression. Neoplasia. 2004;6(4): 390-400.

127. Karin M, Lin A. NF-kappaB at the crossroads of life and death. Nat Immunol. 2002;3(3):221-227.

128. Prince S, Keating S, Fielding C, Brennan P, Floettmann E, Rowe M. Latent membrane protein 1 inhibits Epstein-Barr virus lytic cycle induction and progress via different mechanisms. J Virol. 2003;77(8):5000-5007.
129. Herrero JA, Mathew P, Paya CV. LMP-1 activates NF-kappa B by targeting the inhibitory molecule I kappa B alpha. JVirol. 1995;69(4): $2168-2174$.

130. Huen DS, Henderson SA, Croom-Carter D, Rowe M. The Epstein-Barr virus latent membrane protein-1 (LMP1) mediates activation of NF-kappa B and cell surface phenotype via two effector regions in its carboxy-terminal cytoplasmic domain. Oncogene. 1995;10(3): $549-560$.

131. Mitchell T, Sugden B. Stimulation of NF-kappa B-mediated transcription by mutant derivatives of the latent membrane protein of Epstein-Barr virus. J Virol. 1995;69(5):2968-2976.

132. Yin L, Liao W, Deng X, et al. LMP1 activates NF-kappa B via degradation of I kappa B alpha in nasopharyngeal carcinoma cells. Chin Med J (Engl). 2001;114(7):718-722.

133. Liu SF, Wang H, Li ZJ, et al. Aspirin induces lytic cytotoxicity in Epstein-Barr virus-positive cells. Eur J Pharmacol. 2008;589(1-3): $8-13$.

134. Ablashi DV, Chatlynne LG, Whitman JE Jr, Cesarman E. Spectrum of Kaposi's sarcoma-associated herpesvirus, or human herpesvirus 8, diseases. Clin Microbiol Rev. 2002;15(3):439-464.

135. Cesarman E, Knowles DM. The role of Kaposi's sarcoma-associated herpesvirus (KSHV/HHV-8) in lymphoproliferative diseases. Semin Cancer Biol. 1999;9(3):165-174.

136. Chang Y, Cesarman E, Pessin MS, et al. Identification of herpesvirus-like DNA sequences in AIDS-associated Kaposi's sarcoma. Science. 1994;266(5192):1865-1869.

137. Boshoff C, Weiss RA. Kaposi's sarcoma-associated herpesvirus. $A d v$ Cancer Res. 1998;75:57-86.

138. Cesarman E, Chang Y, Moore PS, Said JW, Knowles DM. Kaposi's sarcoma-associated herpesvirus-like DNA sequences in AIDS-related body-cavity-based lymphomas. $N$ Engl J Med. 1995;332(18):1186-1191.

139. Keller SA, Schattner EJ, Cesarman E. Inhibition of NF-kappaB induces apoptosis of KSHV-infected primary effusion lymphoma cells. Blood. 2000;96(7):2537-2542.

140. Lei X, Bai Z, Ye F, et al. Regulation of NF-kappaB inhibitor IkappaBalpha and viral replication by a KSHV microRNA. Nat Cell Biol. 2010;12(2):193-199.

141. Paul AG, Sharma-Walia N, Chandran B. Targeting KSHV/HHV-8 latency with COX-2 selective inhibitor nimesulide: a potential chemotherapeutic modality for primary effusion lymphoma. PLoS One. 2011;6(9):e24379.

142. George Paul A, Sharma-Walia N, Kerur N, White C, Chandran B. Piracy of prostaglandin E2/EP receptor-mediated signaling by Kaposi's sarcoma-associated herpes virus (HHV-8) for latency gene expression: strategy of a successful pathogen. Cancer Res. 2010;70(9):3697-3708.

143. Sharma-Walia N, Paul AG, Bottero V, et al. Kaposi's sarcoma associated herpes virus (KSHV) induced COX-2: a key factor in latency, inflammation, angiogenesis, cell survival and invasion. PLoS Pathog. 2010;6(2):e1000777.

144. Sharma-Walia N, Raghu H, Sadagopan S, et al. Cyclooxygenase 2 induced by Kaposi's sarcoma-associated herpesvirus early during in vitro infection of target cells plays a role in the maintenance of latent viral gene expression. J Virol. 2006;80(13):6534-6552.

145. Sharma-Walia N, Chandran K, Patel K, Veettil MV, Marginean A. The Kaposi's sarcoma-associated herpesvirus (KSHV)-induced 5-lipoxygenase-leukotriene B4 cascade plays key roles in KSHV latency, monocyte recruitment, and lipogenesis. J Virol. 2014;88(4): 2131-2156.

146. Paul AG, Chandran B, Sharma-Walia N. Cyclooxygenase-2prostaglandin E2-eicosanoid receptor inflammatory axis: a key player in Kaposi's sarcoma-associated herpes virus associated malignancies. Transl Res. 2013;162(2):77-92.

147. Paul AG, Chandran B, Sharma-Walia N. Concurrent targeting of eicosanoid receptor 1/eicosanoid receptor 4 receptors and COX-2 induces synergistic apoptosis in Kaposi's sarcoma-associated herpesvirus and Epstein-Barr virus associated non-Hodgkin lymphoma cell lines. Transl Res. 2013;161(6):447-468. 
148. Sharma-Walia N, Patel K, Chandran K, et al. COX-2/PGE2: molecular ambassadors of Kaposi's sarcoma-associated herpes virus oncoproteinv-FLIP. Oncogenesis. 2012;1:e5.

149. Sharma-Walia N, George Paul A, Patel K, Chandran K, Ahmad W, Chandran B. NFAT and CREB regulate Kaposi's sarcoma-associated herpesvirus-induced cyclooxygenase 2 (COX-2). JVirol. 2010;84(24): 12733-12753.

150. Marginean A, Sharma-Walia N. Lipoxins exert antiangiogenic and anti-inflammatory effects on Kaposi's sarcoma cells. Transl Res. 2015; 166(2):111-133.

151. Folkman J. Tumor angiogenesis: therapeutic implications. NEngl J Med. 1971;285(21):1182-1186.

152. Masood I, Porter KE, London NJ. Endothelin-1 is a mediator of intimal hyperplasia in organ culture of human saphenous vein. Br J Surg. 1997;84(4):499-503.

153. Masood R, Cai J, Zheng T, Smith DL, Naidu Y, Gill PS. Vascular endothelial growth factor/vascular permeability factor is an autocrine growth factor for AIDS-Kaposi sarcoma. Proc Natl Acad Sci U S A. 1997;94(3):979-984.

154. Masood R, Xia G, Smith DL, et al. Ephrin B2 expression in Kaposi sarcoma is induced by human herpesvirus type 8 : phenotype switch from venous to arterial endothelium. Blood. 2005;105(3):1310-1318.

155. Masood R, Zheng T, Tupule A, et al. Kaposi's sarcomaassociated herpesvirus infection and multiple myeloma. Science. 1997;278(5345):1970-1971; author reply 1972-1973.

156. Kieran MW, Kalluri R, Cho YJ. The VEGF pathway in cancer and disease: responses, resistance, and the path forward. Cold Spring Harb Perspect Med. 2012;2(12):a006593.

157. Alghisi GC, Ruegg C. Vascular integrins in tumor angiogenesis: mediators and therapeutic targets. Endothelium. 2006;13(2):113-135.

158. Sivakumar R, Sharma-Walia N, Raghu H, et al. Kaposi's sarcomaassociated herpesvirus induces sustained levels of vascular endothelial growth factors $\mathrm{A}$ and $\mathrm{C}$ early during in vitro infection of human microvascular dermal endothelial cells: biological implications. J Virol. 2008;82(4):1759-1776.
159. Ford PW, Hamden KE, Whitman AG, McCubrey JA, Akula SM. Vascular endothelial growth factor augments human herpesvirus-8 (HHV-8/KSHV) infection. Cancer Biol Ther. 2004;3(9):876-881.

160. Wang L, Wakisaka N, Tomlinson CC, et al. The Kaposi's sarcomaassociated herpesvirus (KSHV/HHV-8) K1 protein induces expression of angiogenic and invasion factors. Cancer Res. 2004;64(8): 2774-2781.

161. Miles SA, Rezai AR, Salazar-Gonzalez JF, et al. AIDS Kaposi sarcoma-derived cells produce and respond to interleukin 6. Proc Natl Acad Sci U S A. 1990;87(11):4068-4072.

162. Li X, Liang D, Lin X, Robertson ES, Lan K. Kaposi's sarcomaassociated herpesvirus-encoded latency-associated nuclear antigen reduces interleukin- 8 expression in endothelial cells and impairs neutrophil chemotaxis by degrading nuclear p65. JVirol. 2011;85(17): 8606-8615.

163. Arav-Boger R. Treatment for Kaposi sarcoma herpesvirus: great challenges with promising accomplishments. Virus Genes. 2009;38(2):195-203.

164. Coen N, Duraffour S, Snoeck R, Andrei G. KSHV targeted therapy: an update on inhibitors of viral lytic replication. Viruses. 2014;6(11): 4731-4759.

165. Uldrick TS, Whitby D. Update on KSHV epidemiology, Kaposi Sarcoma pathogenesis, and treatment of Kaposi Sarcoma. Cancer Lett. 2011;305(2):150-162.

166. Funk CD, FitzGerald GA. COX-2 inhibitors and cardiovascular risk. $J$ Cardiovasc Pharmacol. 2007;50(5):470-479.

167. Shara M, Stohs SJ. Efficacy and safety of white willow bark (Salix alba) extracts. Phytother Res. 2015;29(8):1112-1116.

168. Janakiram NB, Rao CV. Role of lipoxins and resolvins as antiinflammatory and proresolving mediators in colon cancer. Curr $\mathrm{Mol}$ Med. 2009;9(5):565-579.
Journal of Inflammation Research

\section{Publish your work in this journal}

The Journal of Inflammation Research is an international, peer-reviewed open-access journal that welcomes laboratory and clinical findings on the molecular basis, cell biology and pharmacology of inflammation including original research, reviews, symposium reports, hypothesis formation and commentaries on: acute/chronic inflammation; mediators of inflamma-

\section{Dovepress}

tion; cellular processes; molecular mechanisms; pharmacology and novel anti-inflammatory drugs; clinical conditions involving inflammation. The manuscript management system is completely online and includes a very quick and fair peer-review system. Visit http://www.dovepress.com/ testimonials.php to read real quotes from published authors. 